ALTERIDADES, 2020, 30 (60): Págs. 9-20 www.doi.org/ $10.24275 / \mathrm{uam} / \mathrm{izt} / \mathrm{dcsh} /$ alt / 2020v30n60/Canelas

\title{
La acción político-cultural de la administración Messias Bolsonaro*
}

\author{
The political-cultural action \\ of the Messias Bolsonaro administration
}

\author{
ANTONIO ALBINO CANELAS RUBIM**
}

\begin{abstract}
The text seeks to analyze the political-cultural performance of Messias Bolsonaro's management (20192020). The procedures used for the text's construction were: bibliographic research and research in newspapers, social networks, magazines and websites. The analysis of ongoing events is always laden with difficulties, either due to the small amount of pre-existing studies on the theme, or because the developments of events have not yet fully surfaced giving whole meaning to what has happened. Such risks and the confrontation of said risks give value and originality to this text, opening the way for new reflections on the subject. The article's main conclusion is that Messias Bolsonaro's brutal and destructive political-cultural performance has sofar not been able to shape effective cultural policies in the extreme right, given the democratic struggle, including the majority resistance of the cultural field to the onslaught of presidential management.
\end{abstract}

Key words: cultural policies, Brazil, cultural field, democracy, cultural war, resistance

\section{Resumen}

El texto busca analizar el desempeño político-cultural de la gestión de Messias Bolsonaro (2019-2020). Los procedimientos utilizados para su construcción fueron: búsqueda bibliográfica e investigación en periódicos, redes sociales, revistas y sitios web. El análisis de hechos en curso siempre trae dificultades, ya sea por la poca cantidad de estudios preexistentes sobre el tema, o porque los desarrollos de los hechos aún no han salido a la luz, dando sentido a lo sucedido. Tales riesgos y su confrontación dan valor y originalidad al texto, lo que abre el camino a nuevas reflexiones sobre el tema. La principal conclusión del artículo es que la brutal y destructiva actuación político-cultural de Messias Bolsonaro no ha podido, hasta el momento, moldear políticas culturales efectivas en la extrema derecha, dada la lucha democrática, incluida la resistencia mayoritaria del campo cultural al embate de la gestión presidencial. Palabras clave: políticas culturales, Brasil, campo cultural, democracia, guerra cultural, resistencia

\footnotetext{
* Artículo recibido el 30/03/20 y aceptado el 08/05/20. Traducción de Eduardo Nivón Bolán.

** Universidade Federal da Bahia, Programa Multidisciplinar de Pós-Graduação em Cultura e Sociedade (Pós-Cultura). Rua Augusto Viana, s/n - Palácio da Reitoria, Canela, Salvador - CEP: 40110-909 <albino.rubim@gmail.com>.
} 


\section{Introducción}

$\mathrm{E}^{1}$ 1 golpe mediático-jurídico-parlamentario ${ }^{1}$ de 2016 y las elecciones antidemocráticas de 2018 instalaron en Brasil un estado de excepción con repercusiones en toda la sociedad y retrocesos en las políticas públicas. El artículo prioriza un enfoque descriptivo-analítico para acompañar el desempeño político-cultural de la administración de Mesías Bolsonaro $^{2}$ (desde su toma de posesión en enero de 2019), aportando información fáctica necesaria para la comprensión de su actividad, incluso por parte de los lectores alejados del conocimiento de los hechos político-culturales actuales en Brasil. La opción fue elaborar un texto en intenso diálogo con la singular situación política y cultural que vive el país. Dos preguntas centrales sirvieron para orientar la elaboración del artículo. La primera se cuestiona si el desempeño político-cultural del gobierno de Messias Bolsonaro logró configurar rigurosamente una política cultural, y la segunda se refiere a la evaluación de las relaciones entre la llamada guerra cultural, librada por el campo político bolsonarista, y la democracia.

Ambos asuntos podrían tratarse en un horizonte más teórico-conceptual, si se utiliza la bibliografía existente sobre los dilemas de la democracia o sobre el concepto de políticas culturales. En un estudio previo (Rubim, 2019a) se siguió el camino teórico-conceptual de la noción de políticas culturales en un entorno latinoamericano, con el objetivo de actualizar el famoso concepto de Néstor García Canclini (1987 y 2001). La noción que aquí se desarrolla parte del trabajo teóricoconceptual realizado en otro texto esbozado sobre el tema (Rubim, 2019b), y no se reproduce en este espacio. Para el tema de la democracia y la disputa por la hegemonía político-cultural, que le es inherente, este artículo recupera aportes de autores como Antonio Gramsci, Carlos Nelson Coutinho, Norberto Bobbio, Boaventura de Souza Santos, Leonardo Avritzer, entre otros. Se recurre a tales estudiosos sólo como premisas implícitas de los análisis, sin necesidad de introducir una discusión explícita y detallada de las tesis de estos y otros autores.

Investigar la situación político-cultural brasileña contemporánea, que comprende los años 2019 y 2020 , evidentemente trajo dificultades en relación con la bibliografía disponible, que fue bastante reducida debido al carácter muy reciente del tema examinado. El uso de fuentes como periódicos, revistas y redes sociales y sus datos y análisis se ha vuelto inevitable, como casi siempre ocurre con los estudios actuales. La lectura sistemática del semanario CartaCapital en ese periodo sirvió para trazar la trama de los hechos políticos y culturales más relevantes y permitir desde ellos la complementación de informaciones y reflexiones por medio de la investigación en otros vehículos de comunicación. La pandemia y la agilidad de las fuentes digitales impusieron las ediciones virtuales como fuentes prioritarias, a excepción de la revista CartaCapital, a cuya versión impresa se accede mediante suscripción.

Para concluir tales observaciones sobre los dispositivos teórico-conceptual-metodológicos conviene señalar que la inserción del autor del artículo en el propio entorno de estudio tiene implicaciones para la posibilidad de conocimientos que adquieren cierta ambigüedad. Si, por un lado, dicha participación involucra al autor en las tramas en movimiento actuales $\mathrm{y}$, por tanto, impide un alejamiento de su objeto de estudio, por otro lado, dicha inserción permite el acceso a la información, el análisis, las reflexiones y el clima de la coyuntura político-cultural, imposible de captar a distancia. De hecho, en una de sus cartas desde la cárcel, Antonio Gramsci señaló su dificultad para analizar la coyuntura, a causa de la imposibilidad de sentir el clima político-cultural del contexto como resultado de su encarcelamiento y de la prohibición de su convivencia en el entorno de vida de las personas.

Brasil vivió entre 2003 y 2016 un momento único. En ese periodo histórico las clases dominantes no dominaban al gobierno nacional, como sucedió durante siglos, pero permanecieron en el poder. Con limitaciones -debido a circunstancias, alianzas y reconciliaciones-, el gobierno desarrolló políticas de distribución para combatir la enorme desigualdad social existente y políticas de reconocimiento, y buscó hacer visibles y dotar de legitimidad a los sectores oprimidos, siempre excluidos en la vida nacional.

Entre 2003 y 2016, con éxitos y errores, se implantaron políticas dirigidas a las diversidades social y cultural brasileñas, a pesar de que asumieron tonos desiguales en los gobiernos de Luiz Inácio Lula

\footnotetext{
1 Golpe mediático-jurídico-parlamentario es una caracterización polémica del proceso que llevó a la destitución de la presidenta Dilma Rousseff. El concepto tiene distintos usos, pero en este texto se usa para designar una anormalidad democrática en la que hay una continuidad en la destitución de la presidenta, la anulación de la candidatura de Luiz Inácio Lula da Silva y la ofensiva contra las instituciones culturales y educativas en el periodo reciente. Una interpretación de esta situación desde el punto de vista de la comunicación puede encontrarse en Ramos, 2017 [todas las notas son del traductor].

2 El nombre del presidente de Brasil es Jair Messias Bolsonaro.
} 
da Silva (2003-2010) y Dilma Rousseff (2010-2016). Los brasileños experimentaron dos momentos diferentes: el periodo del presidente Lula y los ministros de cultura Gilberto Gil y Juca Ferreira, con un fuerte desempeño político-cultural, y el de la presidenta Dilma y sus ministras de cultura, Ana de Holanda y Marta Suplicy, con un nivel menos relevante de intervención político-cultural (Rubim, 2015; Calabre, 2015).

A pesar de las ambigüedades y contradicciones, la innovación de las políticas culturales, la creatividad de los programas y proyectos y la amplitud de la participación de los agentes culturales colocaron al Ministerio de Cultura en un horizonte político nunca alcanzado en la historia de la nación, especialmente durante el gobierno de Lula y la gestión ministerial de Gilberto Gil. Entre 2003 y 2008, Brasil experimentó una época brillante de políticas culturales en el país, ya sea por el desarrollo de múltiples experiencias creativas o por la ampliación de los estudios sobre políticas culturales.

Aunque a ritmos desiguales, marcados por avances y reveses, ambigüedades y posicionamientos, el Brasil reciente (2003-2016) puso en el orden del día el tema de la cultura y las políticas culturales. La riqueza de esta actuación repercutió en la actitud mayoritaria del campo cultural contraria al golpe (2016), a la administración Temer (2016-2018) y a los desdoblamientos políticos resultado de la elección fraudulenta de 2018 , que impuso la extrema derecha en el gobierno federal. La mayor parte del campo cultural tuvo posiciones claras en relación con la candidatura presidencial de Lula, su escandaloso arresto político, su destitución arbitraria de la carrera presidencial y su reemplazo por el candidato Fernando Haddad. La campaña Lula Livre, por ejemplo, recibió apoyo y participación de una parte significativa y representativa de la comunidad cultural brasileña.

\section{El mandato de Bolsonaro y la intervención en la cultura (enero 2019 en adelante)}

Los gobiernos del estado de excepción Temer y Bolsonaro comparten la animosidad contra la cultura, con episodios explícitos de censura y agresiones a los productos culturales, y la intención de desmantelar las políticas, programas y proyectos culturales inaugurados de 2003 a 2016. Sin embargo, vale la pena señalar la diferente escala de tales procesos. Temer intentó extinguir el Ministerio de Cultura y fracasó debido al movimiento desencadenado por el campo cultural que ocupó las sedes del ministerio en todo el país (Barbalho, 2017 y 2018). Bolsonaro profundizó el ímpetu para desmantelar la institucionalidad del sector cultural con la extinción del Ministerio de Cultura y su reducción a una mera secretaría, vinculada fortuitamente al Ministerio de Ciudadanía y luego, en noviembre de 2019, al Ministerio de Turismo. Además, en poco más de un año de gestión, los responsables institucionales del área federal de cultura ya han sumado cinco nombres: Henrique Pires (hasta agosto de 2019), Ricardo Braga (agosto-septiembre 2019), Roberto Alvim (septiembre de 2019-enero de 2020), Regina Duarte (marzo-mayo de 2020) y Mario Frías (junio de 2020 en delante).

La gestión de Bolsonaro ha elegido la cultura como enemigo, junto con la educación, la ciencia, las artes, las universidades públicas y los temas relacionados con las llamadas minorías, en especial las manifestaciones de género, los afrobrasileños, LGBT y los pueblos indígenas. En el caso de la cultura, el gobierno se caracteriza por las agresiones a las libertades de creación y expresión, por el retorno de la censura, por el desmantelamiento de las instituciones culturales, por la demonización de la cultura y las artes y por la intención deliberada de asfixiarlas financieramente.

Los episodios en este horizonte de ataques se incrementan. Imposible enumerarlos todos. Como ejemplo, sólo cabe mencionar algunas intervenciones públicas de Roberto Alvim, por su presencia emblemática en la escena político-cultural del actual gobierno. Después
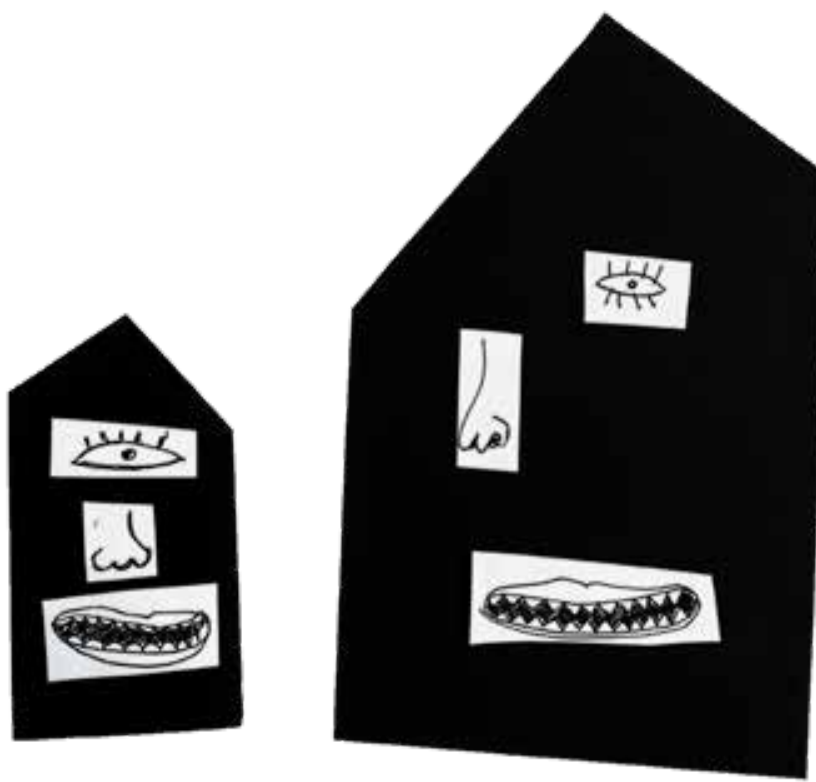
de insultar de manera verbal a Fernanda Montenegro, llamando a la actriz "mentirosa" y "sórdida”, dejó la dirección del Centro de Artes Escénicas de la Fundación Nacional de las Artes (Funarte) ${ }^{3}$ para ser promovido por Messias Bolsonaro a la Secretaría de Cultura. La agresión contra la actriz tuvo enormes repercusiones negativas en el país y en el extranjero. Vale la pena recordar que Montenegro es una de las actrices brasileñas más conocidas y respetadas en el país y en el extranjero; una especie de primera dama de las artes. ${ }^{4}$

Ya en el cargo de secretario de Cultura, Roberto Alvim hizo, en la reunión anual de la Organización de las Naciones Unidas para la Ciencia, la Educación y la Cultura (Unesco), un severo ataque a las artes brasileñas de los últimos veinte años, sorprendiendo a las delegaciones extranjeras presentes en el evento por lo que era una actitud inusual en un ambiente marcado por delicadas reglas diplomáticas, y que provocó gran vergüenza internacional para Brasil. ${ }^{5}$

Ricardo Alvim había dicho en varias ocasiones que el país estaba viviendo un momento crucial de la guerra cultural. Anunció que estaba formando un ejército combatiente de artistas espiritualmente comprometidos con el presidente de extrema derecha para redefinir la historia cultural nacional. El 2 de diciembre de 2019 el ejército para la guerra cultural llegó a tener dos nuevos miembros nombrados por Messias Bolsonaro, uno era el maestro y youtuber Dante Mantovani, designado presidente de Funarte, quien pronto mostró sus credenciales al afirmar que el rock fomenta el sexo y conduce al aborto y al satanismo y que los Beatles surgieron para implementar el comunismo. ${ }^{6} \mathrm{El}$ otro fichaje fue Rafael Nogueira ${ }^{7}$ (monárquico, maestro, youtuber y seguidor del astrólogo/ideólogo-mayor del gobierno Olavo de Carvalho), nombrado director de la Biblioteca Nacional y quien también asumió un tono belicoso al asociar a los cantantes Caetano Veloso y Gabriel Pensador y a la banda Legião Urbana con el analfabetismo. Otro miembro del ejército cultural tardíamente incorporado fue Sérgio Nascimento de Camargo, hijo de un activista del movimiento negro y nombrado miembro de la Fundación Cultural Palmares, una entidad nacional centrada en las culturas negras. Camargo declaró, entre otras perlas, que la esclavitud fue beneficiosa para los africanos y que Brasil tiene un racismo "Nutella".

CartaCapital, en su edición del 11 de diciembre de 2019, dedicó su portada y reportaje principal al tema. En la portada, las fotografías de Wagner Moura, Chico Buarque, Fernanda Montenegro, Gilberto Gil y Caetano Veloso tenían la boca rota y una franja roja de prohibido. Abajo de la imagen se leía el encabezado: "Cállate. El gobierno de Bolsonaro expande la 'guerra cultural' contra los artistas". El título del reportaje de Eduardo Nunomoura, Jotabê Medeiros y Pedro Alexandre Sanches es contundente: "La guerra cultural a todo vapor. El bolsonarismo extiende el asedio a los artistas brasileños y elige a la clase como el enemigo para ser aniquilado". El informe, que ocupa las páginas 14 a 19, ofrece un panorama general de las numerosas acciones que el gobierno ha realizado para dañar el área cultural, relatando varios episodios que demuestran la guerra continua y deliberada contra los más diferentes sectores y personalidades del campo cultural brasileño. Algunos de estos eventos ya los he relatado en este texto.

3 Fundação Nacional de Artes.

4 La actriz Fernanda Montenegro (1929) ha recibido grandes reconocimientos en su país y fuera de él. En 1998 fue nominada a los premios Oscar como mejor actriz por Estación Central de Brasil y ganó un Emmy por Doce de Mae en 2013. Celebró su 90 aniversario con la publicación de su autobiografía Prólogo, Ato, Epílogo ocasión que le sirvió para dirigir diversas críticas al régimen, sobre todo a la política cultural. Por ello, en septiembre de 2019, Roberto Alvim, en ese momento director del Centro de Artes Escénicas de Funarte, posteó en las redes sociales fuertes reproches a la artista llamándola "sórdida" y "mentirosa". La edición digital Epoca de O Globo publicó por ese motivo un perfil del que iba a ser efímero secretario de Cultura: "Quem é Roberto Alvim, o artista convertido ao bolsonarismo que atacou Fernanda Montenegro”. El artículo hace referencia varias veces a su llamado a la guerra cultural <https: / / epoca.globo.com/cultura/quemroberto-alvim-artista-convertido-ao-bolsonarismo-que-atacou-fernanda-montenegro-23976446>.

5 "Na Unesco, Roberto Alvim diz que a arte brasileira escravizou a mente do povo. Em reunião em Paris, discurso contra influência 'esquerdista' na cultura chamou atenção de delegações estrangeiras" <https: / / www1 .folha.uol.com.br/ilustrada/ 2019/11/na-unesco-roberto-alvim-diz-que-a-arte-brasileira-escravizou-a-mente-do-povo.shtml>.

6 Con motivo de su designación a la dirección de Funarte, la sección de la red g1.globo publicó un perfil del músico y filósofo destacando algunas de sus extrañas consideraciones sobre el arte y la cultura recientes de Brasil y el mundo: "Dante Mantovani, novo presidente da Funarte, é maestro e disse que 'rock leva ao aborto e ao satanismo" <https://g1.globo. com / pop-arte/noticia/2019/12/02/dante-mantovani-novo-presidente-da-funarte-e-maestro-e-disse-que-rock-levaao-aborto-e-ao-satanismo.ghtml>.

7 Al ser nombrado director de la Biblioteca Nacional, Nogueira (1984) dio una entrevista en la que aclaraba puntos de vista sobre su simpatía por la monarquía, la crítica a Caetano Veloso por favorecer el analfabetismo, su negación del terraplanismo y la aceptación de Olavo de Carvalho como su maestro: "Olavista, monarquista, mas não terraplanista: as ideias de Rafael Nogueira para a Biblioteca Nacional" < https: / /www.gazetadopovo.com.br/vida-e-cidadania/olavista-monarquistamas-nao-terraplanista-as-ideias-de-rafael-nogueira-para-a-biblioteca-nacional/>. 
La edición brasileña del diario español El País publicó el 27 de diciembre de 2019 un artículo de Joana Oliveira titulado "Bajo ataque de Bolsonaro, Cultura defiende su impacto en la economía con ingresos de 170 billones de reales". ${ }^{8} \mathrm{El}$ informe demostraba el papel económico de la cultura en Brasil, afirmando que el "Sector emplea a unas 5 millones de personas, entre formales e informales, casi $6 \%$ de toda la fuerza laboral brasileña" y que la "Ley Rouanet apoya a 73\% de las producciones culturales del país”. La llamada ley Rouanet es la legislación brasileña de incentivos fiscales a la cultura. En resumen, a pesar de los números impresionantes de la dimensión económica del sector, con evidente impacto en el desarrollo de Brasil, la cultura está bajo un cerrado y constante bombardeo por parte del gobierno.

El 17 de enero de 2020, en un discurso sobre la convocatoria al Premio Nacional de las Artes, bajo acordes de Richard Wagner, el compositor favorito de Adolf Hitler, el secretario de Cultura Roberto Alvim plagió extractos de un discurso de Joseph Goebbels, ministro de Propaganda de la Alemania nazi. En el video, Roberto Alvim afirma: "El arte brasileño de la próxima década será heroico y será nacional. Estará dotado con una gran capacidad de participación emocional y será igualmente dominante [...] o de lo contrario no será nada”. Y el líder nazi había dicho: "El arte alemán de la próxima década será heroico [...], será nacional, enormemente emocional e igualmente dominante [...] o de lo contrario no será nada". La repercusión política de una actitud ideológica tan explícita fue intensa. Reaccionaron varios segmentos sociales y políticos, lo que llevó a la destitución del secretario por parte de Messias Bolsonaro.

Además del episodio escenificado que parafraseó al nazismo, la caída de Roberto Alvim de la Secretaría de Cultura también pareció sugerir que su ambicioso movimiento, que buscaba ocupar el papel principal en la guerra cultural contra la izquierda, no agradó a los sectores ideológicos del régimen, sometidos al gurú Olavo de Carvalho y dispersos en varios órganos de gobierno relevantes, como el Ministerio de Educación y el Ministerio de Relaciones Exteriores, así como asociados con sectores evangélicos fundamentalistas, que pretenden imponer una agenda de valores conservadores. ${ }^{9}$ Olavo de Carvalho, quien nombró a
Roberto Alvim para el cargo, por ejemplo, escribió en Facebook: "Es demasiado pronto para juzgar, pero Roberto Alvim puede no estar muy bien en la cabeza. Ya veremos”. Además de su falta de articulación y base política dentro de la administración, la actitud de Roberto Alvim de hacer tan visibles los valores fascistas que gobiernan el régimen parece no haber complacido al propio gobierno y a sus mentores ideológicos, que quizá prefieren no ser tan explícitos.

Para ocupar su puesto fue invitada la actriz, vinculada a telenovelas y los seriales de Rede Globo, Regina Duarte. En 1979 ganó fama al protagonizar la serie Malu Mulher, que discutió y afirmó un nuevo lugar de la mujer en la sociedad. Su trayectoria posterior se volvió cada vez más de derecha, con posiciones siempre opuestas a los sectores de izquierda y, en particular, al Partido de los Trabajadores. En las elecciones de 2018 declaró su apoyo a Messias Bolsonaro, un caso relativamente raro entre artistas y miembros más conocidos del campo cultural.

Su toma de posesión tuvo lugar el 4 de marzo de 2020. La ceremonia estuvo marcada por la débil presencia de los sectores cultural y artístico. Su discurso trató, entre aspavientos y chistes, de la cultura como algo divertido, como una especie de "pedo de payaso", metáfora que ella enunció de manera abierta. Según la revista Fórum dijo literalmente: "La cultura es el pum producido con talco salpicado del trasero del payaso. La cultura es así, está hecha de payasadas". ${ }^{10} \mathrm{En}$ el discurso de sólo 15 minutos, además de este extracto que ganó mucha visibilidad por lo grotesco, la secretaria de Cultura recordó que tendría carta blanca del presidente para elegir a su equipo.

El día anterior, sin haber tomado aún posesión del cargo, Regina Duarte despidió a siete miembros de órganos vinculados a la secretaría, entre ellos a los presidentes de Funarte y al del Instituto Brasileño de Museos (Ibram), todos ellos designados por el mayor ideólogo de Messias Bolsonaro y familia: Olavo de Carvalho. Tal actitud fue vista por el ala olavista del gobierno como una declaración de guerra. No pasó mucho tiempo antes de que las autoridades y los sitios web reaccionaran haciendo feroces críticas a la nueva secretaria, incluido el propio Olavo de Carvalho, quien emitió palabras vulgares contra Regina Duarte en las redes sociales.

\footnotetext{
8 https://brasil.elpais.com/cultura/2019-12-27/sob-ataque-de-bolsonaro-cultura-defende-seu-impacto-na-economiacom-receita-de-170-bilhoes-de-reais.html

9 Para el estreno del régimen de Bolsonaro Pablo Stefanoni preparó un perfil de Olavo de Carvalho publicado en la edición digital de Nueva Sociedad (Stefanoni, 2019). En su texto presenta diversas viñetas de su extraño pensamiento filosófico y de su ideología política.

${ }^{10}$ Revistaforum.com.br (4 de marzo de 2020).
} 
Poco después, el blog de Lauro Jardim alojado en el sitio de $O$ Globo $^{11}$ destacó que ocho personas nombradas por Duarte para ocupar cargos en la Secretaría de Cultura habían sido vetadas por el Palacio Planalto, sede de la administración federal. Un ejemplo fue su intento fallido de colocar a Maria do Carmo Brant de Carvalho en la Secretaría de la Diversidad. Otro, aún más grave, es que no pudo deshacerse de Sérgio Camargo en la Fundación Cultural Palmares y tuvo que leer una respuesta de él al link en el que Regina Duarte lo acusaba de "activista”. En su Twitter, Camargo envió un mensaje a su jefa: "No acepto izquierdistas en el gobierno de Bolsonaro. Por el contrario, los voy a quitar". ${ }^{12}$

En definitiva, la secretaria tuvo que moverse, con una habilidad que no tenía, tanto en relación con la postura mayoritariamente crítica de la comunidad cultural hacia el gobierno de Messias Bolsonaro y su agresiva actitud contra la cultura, como en el interior del propio gobierno desde donde fue atacada por las fracciones más fundamentalistas e ideológicas de ultraderecha. Sus posibilidades de acción fueron limitadas por su falta de consistencia, formación y experiencia, así como por el comportamiento del gobierno que insiste en atacar la cultura, y por los extremos y disputas dentro de la propia administración federal. En la página 12 de la sección de noticias de la semana de CartaCapital aparecía: "La participación especial de Regina Duarte en esta telenovela puede ser más corta de lo imaginado, apostamos a favor de los políticos de la capital federal" ( 18 de marzo de 2020).

Las apuestas resultaron ciertas. El 20 de mayo de 2020, 78 días después de su toma de posesión, Regina Duarte y Messias Bolsonaro protagonizaron un bochornoso video de despedida frente al palacio. Entre sonrisas amargas, falsas y forzadas, ella supo afirmar que ganó un regalo, "un sueño para cualquiera en comunicación, audiovisual, cine, teatro, una invitación a hacer Cinemateca”. La farsa olvidó dos aspectos esenciales: la institución, dedicada a la colección de imágenes en movimiento brasileñas, atraviesa la mayor crisis de su historia, debido a la falta total de apoyo del gobierno federal, y no había un puesto disponible para hacer real el regalo para Regina Duarte. De su fugaz paso por la Secretaría no quedaron más que actitudes vergonzosas, como no hacer pública ninguna moción de lamento por la muerte de grandes artistas, como João Gilberto, Aldir Blanc y Moraes Moreira, además de algunas entrevistas desastrosas, como la concedida a CNN Brasil, el 7 de mayo, donde minimizó la dictadura civil-militar y de la cual escapó antes de finalizar la entrevista. La revista CartaCapital, del 27 de mayo de 2020, publicó un artículo titulado "El pedo del payaso", informando su paso y su grotesco acto de despido.

Casi un mes después, el actor de telenovelas en Rede Globo y TV Record, Mário Frias, de 48 años, asumió el cargo en la Secretaría Especial de Cultura. Su inauguración fue restringida e informada por el Ministerio de Turismo en una red social en la noche del 23 de junio, luego de haber ocurrido. No hubo presencia de invitados ni de prensa. El acto tuvo lugar en el despacho del ministro Marcelo Álvaro Antonio, a diferencia del acto de toma de posesión de Regina Duarte, abierto a invitados y al que asistió Messias Bolsonaro. Desde que ocupó el cargo, la acción más visible del nuevo secretario ha sido acusar al PT, una vez más, de uso político de la ley Rouanet de incentivo fiscal, mostrando desconocimiento de sus procedimientos de selección y el deseo de complacer al nuevo jefe. La Secretaría Nacional de Cultura del PT repudió la actitud de la "nueva" Secretaría Especial de Cultura.

En el escenario actual de la gestión de Bolsonaro parece que la Secretaría de Cultura está destinada a ocupar un lugar secundario, dado que la guerra cultural, tan querida por los actos de gobierno, ya tiene sus protagonistas debidamente definidos. La Secretaría de Cultura, ahora con Mário Frias a la cabeza, debe permanecer marginal, e incluso puede asumir un papel a todas luces ornamental dentro de la gestión.

El desmantelamiento y el desprecio por el ámbito institucional de la cultura están vinculados a los ataques cotidianos al campo cultural. Dos textos recientes denuncian que estos procesos continúan ocurriendo en paralelo con la parálisis total de la Secretaría Especial de Cultura. El "Manifiesto de los Servidores de la Cultura", del Foro de Cultura, que reúne a varias asociaciones, y el artículo "Cultura y barbarie”, firmado por Juca Ferreira y Alfredo Manevy y publicado en Folha de São Paulo, reiteran la dramática situación de la cultura.

\footnotetext{
11 blogs.oglobo.globo.com

${ }^{12}$ Como ya se ha señalado, Camargo es una figura polémica, pues es un periodista negro que niega el racismo como un problema social en Brasil. En las redes sociales presumió de haberse mantenido al frente de la Fundación Palmares a pesar de la intención de la secretaria de Cultura de retirarlo del cargo. No acudió a la toma de posesión de Regina Duarte, a quien considera de izquierda <https: / / www.metropoles.com/brasil/politica-brasil/sergio-camargo-ironiza-reginaduarte-ao-ser-chamado-de-problema>.
} 


\section{Guerra cultural}

La actuación anticultural, común a todos los regímenes autoritarios, como el estado de excepción que hoy oprime a Brasil, no se limita a la postura destructiva ya señalada. Paralelamente al desmantelamiento y persecución de la cultura, similar a lo ocurrido entre 2016-2018 en la administración Temer, con el aumento de la agresividad actual surgen nuevos factores fundamentales que distinguen la situación vivida con Temer de la experimentada con Bolsonaro, y permiten diferenciar con mayor claridad la singularidad del momento político-cultural que vive el país hoy en día.

Sin embargo, la política de gestión de Messias Bolsonaro no parece pretender sólo destruir, por mucho que sea su imagen más visible. La radicalidad del desmantelamiento, en varios ámbitos y en la cultura, esconde otro aspecto nada despreciable del desempeño de la actual dirección. Desde esta perspectiva, es difícil seguir, sin más, la propuesta de que el país pasó de un Estado cultural -con énfasis en el gobierno de Lula y las administraciones Gil/Juca- a uno anticultural, como lo sugieren Guilherme Varella y João Brant (2020). Por mucho que el gobierno de Messias Bolsonaro, con su carácter destructivo, lesione de manera brutal innumerables campos culturales, no parece que no pretenda y no logre imponer una cultura autoritaria, que exacerba la intolerancia y aniquila los valores democráticos, en lugar de la cultura existente hoy, en la cual aún coexisten elementos contrastantes e incluso antagónicos. Éste es el choque fundamental que se vive en Brasil y es mejor no descartar de antemano estos datos, incluso es necesario intentar superar sus horizontes con una disputa a favor de la hegemonía de una cultura donde predominen los valores emancipatorios y libertarios.

En lugar de la mera persecución a la cultura ha surgido una orientación precisa de la guerra, o más bien de la cruzada ideológica contra el marxismo cultural y todo lo que se ajusta a esta noción elástica. Iná Camargo Costa, en su libro titulado Dialética do marxismo cultural, señala que el uso de esta expresión proviene de principios de la década de 1990, cuando la empezaron a usar fundamentalistas cristianos, ultraconservadores y de extrema derecha de Estados Unidos (Costa, 2020: 37-38). El pensamiento de Olavo de Carvalho, gurú de la familia Bolsonaro, aparece como un probable puente entre la extrema derecha estadounidense y la introducción de la guerra cultural en el país, como se sugiere, por ejemplo, en la entrevista titulada "O Napoleão do sanatório", publicada en las páginas 30-34 de la revista CartaCapital del 14 de noviembre de 2018.
La discusión sobre la guerra cultural y sus singularidades nacionales aún tiene pocos estudios en el país, pero están comenzando a surgir algunas investigaciones. João Cezar de Castro Rocha, profesor de la Universidad Estatal de Río de Janeiro (UERJ), en una entrevista (Rocha, 2020a) y en una introducción (Rocha, 2020b) coloca al libro Orvil como fuente inspiradora de la versión brasileña de la guerra cultural. Este libro es un anagrama mimético creado por los militares para revertir por completo las interpretaciones contenidas en el libro Brasil: Nunca más (1985), que denunciaba la arbitrariedad y la violencia de la dictadura civil-militar brasileña. Según Rocha, la guerra cultural bolsonarista, a pesar de tener relaciones con lo que está sucediendo en el mundo actual, tiene ciertas peculiaridades: la fuente de su concepción del mundo deriva del libro Orvil (Rocha, 2020a: 7) y su técnica discursiva se inspira en la "retórica del odio, enseñada en las últimas décadas por Olavo de Carvalho" (Rocha, 2020b: 2). No cabe duda de que es importante buscar las raíces nacionales de la guerra cultural bolsonarista, pero parece temerario desconocer o incluso menospreciar potentes ideas internacionales que circulan e involucran con gran sintonía con los tiempos oscuros que se viven en el mundo.

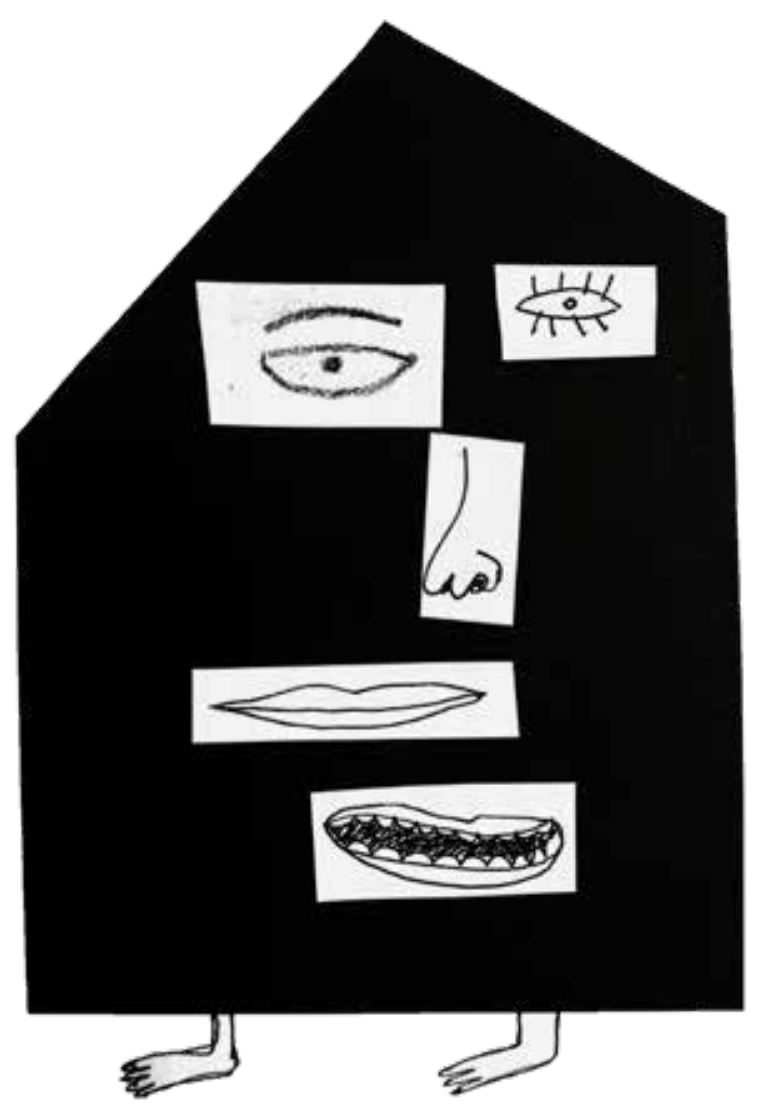


La performance, inspirada en tales concepciones ideológicas, no busca el mero desarrollo de la cultura, las artes, el patrimonio y otras modalidades culturales, ahora con un sesgo autoritario y conservador, sino que desarrolla una feroz cruzada contra todas las modalidades culturales, que a su juicio están contaminadas por el marxismo cultural. Claudio Oliveira observa, de manera perspicaz, que "detrás de la denominación 'marxismo cultural' está presente no sólo la idea de que el marxismo se vuelve cultural [...], sino también la idea de que la cultura se vuelve marxista" (Oliveira, 2020: 5). Tal cruzada se organiza desde el núcleo duro ideológico de la extrema derecha del gobierno, instalado en diversos sectores del aparato estatal nacional, con énfasis en las relaciones internacionales y la educación y con la estricta colaboración de órganos estatales controlados por el fundamentalismo religioso. No se trata sólo de la destrucción, sino de instalar en su lugar otra cultura, visceralmente autoritaria y conservadora, terraplanista, con huellas de intransigente fundamentalismo religioso y moral. Esta novedad del escenario político-cultural nacional no puede ni debe menospreciarse. Indica el peligroso nivel de guerra cultural abierta por la gestión de Messias Bolsonaro.

La cruzada no tiene como polo principal ni está centralizada en la Secretaría de Cultura. El eficaz proceso de descentralización de la ubicación institucional de la guerra cultural explica la singularidad adquirida por la cruzada político-cultural-ideológica en curso. A diferencia de la situación anterior, en la que la derecha en el poder en la administración Temer se concentró en destruir el legado político-cultural de los gobiernos anteriores (2003-2016), ahora la extrema derecha en el poder no sólo continúa con más brutalidad la destrucción de las libertades, las políticas culturales e incluso el campo de la cultura, sino que también pretende poner en lugar de una cultura ciudadana, crítica y laica una cultura autoritaria, conservadora y fundamentalista, en términos políticos, morales y religiosos.

La descentralización institucional del locus formulador de la lucha político-cultural-ideológica en curso revela otra peculiaridad de la situación política experimentada hoy en el país. En estricto sentido, la empresa está organizada bajo las órdenes de la fracción ideológica del gobierno comandada por Olavo de Carvalho, su astrólogo jefe, y por completo asumida por el presidente, la familia Bolsonaro y los líderes gubernamentales. Es decir, la guerra político-culturalideológica no se reduce a un área específica del gobierno, como la Secretaría de Cultura, sino que permea de manera estratégica al propio gobierno, se disemina en varias de sus organizaciones y es aceptada en su totalidad por su núcleo central, instalado en el Palacio de Planalto. Por lo tanto, si la cultura no está inscrita como estratégica en el modelo de desarrollo del país (que, si somos rigurosos, no existe), ella se ha insertado plenamente como estratégica en la lucha de clases en curso en Brasil, en la que se enfrentan diferentes modelos de país.

En este contexto, por adhesión u omisión, el estímulo a las culturas contrarias a las libertades individuales y colectivas, a la democracia, la ciudadanía y la diversidad social y cultural, en especial las relacionadas con las culturas de identidad asociadas con los negros, los pueblos indígenas, las mujeres y las comunidades LGBT, no sólo es implementado de modo estratégico por el gobierno, sino que se ve reforzado por los sectores dominantes y sus principales medios de comunicación. En resumen, esta convergencia política pretende combinar la destrucción de culturas democráticas, emancipadoras, laicas y republicanas con la creación de culturas autoritarias, fundamentalistas, elitistas y moralistas del nuevo viejo Brasil.

El papel otorgado a las "políticas culturales" asociadas con el gobierno de Messias Bolsonaro debe ser discutido en este escenario. Cualquier intención de algo incluso cercano a las políticas culturales sólo parece adquirir sentido en este contexto. En la gestión Bolsonaro, la cultura se instrumentaliza y opera dentro de objetivos muy delimitados, casi sin restos de autonomía, ni siquiera relativa. El impulso eminentemente instrumental de la cultura obstaculiza e inhibe la conformación de una política que busca desarrollar la cultura, aun aquella sintonizada con los valores de la extrema derecha. En esta circunstancia, el gobierno no ha logrado articular hasta ahora una política cultural eficaz en el sentido estricto del término. La construcción de la política cultural requiere un conjunto de requisitos, muchos de los cuales no están a su alcance y otros más son contradictorios con su desempeño político-cultural.

El concepto de política cultural que se indica a continuación, elaborado en diálogo con la famosa noción de Néstor García Canclini (1987 y 2001), puede ser una buena medida de la distancia que debe superarse entre la situación vigente y las condiciones necesarias para hablar de política cultural, guiada por las formulaciones autoritarias, conservadoras y fundamentalistas de la actual administración federal. En el contexto de este artículo, la política cultural se entiende como un conjunto articulado, consciente, continuo, deliberado, sistemático y planificado de intervenciones, formulaciones y/o actuaciones de diversas entidades culturales (Estado, sociedad, comunidades e instituciones 
culturales, etcétera) con el objetivo de satisfacer las demandas y necesidades culturales de la población; estimular el desarrollo simbólico; construir hegemonías para conservar o transformar la sociedad y la cultura y garantizar la ciudadanía y los derechos culturales. La política cultural activa recursos institucionales, de infraestructura, regulatorios, financieros y de personal. Presta especial atención a las dimensiones organizativas de la dinámica cultural. Para que exista, la política cultural exige superar la instrumentalización de la cultura por la política e inaugurar una nueva relación, donde la política sea un instrumento y un propósito cultural (Rubim, 2019b). A diferencia de todo esto, en la gestión de Messias Bolsonaro, una vez más, la cultura se está instrumentalizando como objetivos expresamente político-ideológicos, y muchos de los requisitos señalados en la definición anterior no se están considerando.

\section{Guerra cultural, violencia y los desafíos de la lucha democrática}

Pero tenemos que ser conscientes de un aspecto crucial de esta nueva circunstancia político-cultural. La colocación de la cultura en el centro de la disputa político-ideológica en la sociedad (que, paradójicamente, nunca fue formulada y llevada a cabo por los gobiernos de Lula o Dilma en su proyecto de transformación democrática de Brasil) no significa en modo alguno la aceptación de la lucha por la hegemonía intelectual y moral en el ambiente democrático, como imaginó Antonio Gramsci cuando hizo la distinción entre dominación a través de la coerción y otra realizada por la activación de la cohesión. El llamamiento a la centralidad político-ideológica atribuida a la cultura por la gestión de Messias Bolsonaro no implica la aceptación de un ámbito legítimo de disputa política democrática de valores y concepciones político-culturales diferenciadas que, en consecuencia, deban ser respetadas en principio como tal por todos los ciudadanos y agentes políticos.

La postura de la gestión del Messias Bolsonaro configura algo bastante peligroso: no se trata de que la activación previa de la lucha político-cultural desarrolle la contienda democrática y legítima por el poder político, como podría asumirse ingenuamente, sino que, más bien, significa el uso anticipado e instrumental de tales dispositivos cultural-ideológicos para permitir actos de violencia no sólo simbólicos, sino también físicos, contra instituciones, colectivos y personas, que no se someten a su predicación autoritaria y fundamentalista. Por último, no se trata de un proyecto de disputa de hegemonía cultural (intelectual y moral, como diría Antonio Gramsci), ya que la competencia no se limita a la confrontación para aclarar, sensibilizar y subsidiar la toma de decisiones políticas de manera pacífica con base en procedimientos legales y legitimados por la sociedad brasileña. De hecho, la activación de la visión estratégica de la cultura sólo busca permitir la violencia simbólica y física contra todos los opositores político-culturales, concebidos como enemigos para destruir.

De hecho, la activación de la visión estratégica de la cultura busca hacer posible la violencia simbólica y física contra todos los opositores político-culturales, tomados como enemigos que destruir. No parece una mera coincidencia que, en palabras de los intelectuales bolsonaristas, "el verbo dominante es eliminar. Y el sustantivo dominante es la limpieza”, como lo encuentra el estudio de João Cezar de Castro Rocha (Rocha, 2020a: 4). Tales expresiones remiten, según ese autor, al universo semántico del golpe cívico-militar de 1964.

Por lo tanto, el uso de la expresión guerra cultural en lugar de una disputa por la hegemonía político-cultural adquiere pleno significado, porque tampoco se vive hoy un ambiente democrático en Brasil, sino un estado de excepción con todo tipo de autoritarismo, violación de las leyes y la violencia que él promueve. La distinción entre estas dos concepciones es fundamental, ya que produce y hace posible la profundización de la democracia con la búsqueda de una transición de una democracia puramente formal a una democracia sustantiva, donde se contemplen y garanticen los requisitos formales esenciales para la democracia, pero también donde se asegure a la mayoría de la población sus derechos (económicos, sociales, políticos, ambientales y culturales). La otra opción, asumida por el gobierno actual, puede conducir a un régimen no sólo autoritario, sino totalitario sin más.

La existencia del estado de excepción sitúa la cuestión democrática como vital para superar el retroceso impuesto al país, incluso en el ámbito cultural. No se trata únicamente de luchar por una democracia formal de barniz liberal-electoral, sino de profundizar la lucha por una democracia sustantiva que garantice todas las reglas formales necesarias para el entorno de las libertades democráticas y, más que esto, asegure la ciudadanía y los derechos para todos, incluida la ciudadanía cultural y los derechos culturales. En el (hiper)politizado contexto de Brasil, hoy, más que nunca, el destino de la cultura y las políticas culturales pasa por la cuestión de la democracia, su afirmación o negación plena, con la instalación de un Estado dictatorial declarado. 
La batalla por la democracia requiere asumir la cultura como un momento fundamental en esta lucha. En primer lugar, porque la disputa democrática requiere la configuración de una cultura política democrática, que se oponga de manera enérgica a la cultura autoritaria y fundamentalista que el gobierno y las clases dominantes tratan de imponer a Brasil. Sin la hegemonía de los valores democráticos no hay posibilidad de democracia efectiva en el país. Tal proceso de disputa es vital para la construcción de un Brasil radicalmente democrático. En segundo término porque, en su mayoría, el campo cultural ha sido un agente activo del proceso de lucha democrática en el país desde 2016, actuando contra el golpe de Estado de ese año, confrontando a la administración Temer entre 2016 y 2018, apoyando la candidatura presidencial de Lula en 2018 y, después de su cancelación arbitraria, la candidatura de Fernando Haddad, oponiéndose al candidato (2019) y luego a la administración de Messias Bolsonaro (2019 en adelante) y participando de modo creativo en la campaña Lula livre, por la libertad de Luiz Inácio Lula da Silva, preso político entre 2018 y 2019.

De hecho, la escena político-cultural de Brasil está marcada por una importante politización causada, entre otros factores, por la singular presencia de políticas culturales en los años 2003-2016, como observó Alexandre Barbalho en los textos que he referido más arriba. La politización de los desfiles de las escuelas de samba en Río de Janeiro y São Paulo en los últimos carnavales puede ser tomada como emblemática. Pedro Alexandre Sanches, en el artículo "Das cinzas às cinzas" (De las cenizas a las cenizas), publicado en CartaCapital del 4 de marzo de 2020, analiza la actitud rebelde de las escuelas de samba, pero también señala los límites del espacio-tiempo de tales protestas. Recuerda las actitudes fuertemente críticas de escuelas como: Paraíso da Tuiuti, Mangueira, São Clemente, Águia de Ouro y Gaviões da Fiel.

La politización combinada y desigual de algunos segmentos culturales merece ser estudiada, ya que no parece tener un grado similar al del conjunto del sector cultural examinado: artistas independientes, culturas digitales, culturas eruditas, culturas de identidad, culturas populares, culturas universitarias, industria cultural, entre otros. Estas áreas de la cultura tienen inserciones políticas, sociales y económicas muy diferentes, lo que da lugar a posibilidades desiguales de politización y acción en el escenario de las luchas en Brasil. Por ejemplo, segmentos nacidos en las comunidades universitarias, sobre todo públicas, vinculados a la educación, la ciencia, las artes y la cultura, tienen posiciones abiertamente críticas al gobierno federal. Algo similar parece suceder con agentes culturales relacionados con las culturas identitarias, atacados día a día por miembros y simpatizantes de la administración federal. En el área de las culturas populares, los activistas que han tenido más vínculos con programas culturales, como Cultura Viva, tienen una postura más definida contra el gobierno, mientras que otros permanecen omisos y distantes de las contiendas políticas, a veces atrapados en relaciones paternalistas de bienestar y clientelismo, debido a la precariedad de sus condiciones sociales. En las llamadas culturas eruditas el silencio se aprecia aún mayor, si no es que ofrecen cierto apoyo al gobierno. Algunas actitudes de la administración de Messias Bolsonaro, sin embargo, parecen molestar a parte de sus miembros. Dentro de la industria cultural, con todos los directivos aliados y estrechamente sometidos a las órdenes gubernamentales, muchas celebridades se oponen de forma expresa a Messias Bolsonaro y una fracción minoritaria lo apoya, como los artistas ligados a la música sertaneja, un tipo de música mercantilizada asociada con el mundo rural y la agroindustria. Por su parte, entre los artistas independientes predomina la posición crítica hacia el gobierno, así como entre los jóvenes cercanos a las culturas digitales, aunque hay asimismo partidarios del gobierno y activistas de extrema derecha entre ellos. El estudio de los comportamientos y pensamientos de los agentes y las comunidades culturales se convierte en fundamental para una mejor comprensión del escenario político-cultural brasileño contemporáneo.

En el campo cultural tales desafíos implican la lucha por la preservación crítica de las experiencias de las políticas democráticas de cultura que tuvieron lugar entre 2003 y 2016, que las administraciones Temer y Bolsonaro tratan sistemáticamente de borrar, destruir y silenciar. Como Walter Benjamin señaló, el pasado está en peligro porque está en continua disputa en el presente. En sus famosas tesis sobre la filosofía de la historia, Walter Benjamin escribió de modo poético: "Articular históricamente el pasado no significa conocerlo 'como verdaderamente ha sido'. Significa adueñarse de un recuerdo tal cual éste relampaguea en un instante de peligro" (Benjamin, 1967: 45).

El riesgo se vuelve mayor debido a la situación autoritaria experimentada después del golpe de Estado de 2016 y el ascenso de la extrema derecha al poder federal. La disputa político-cultural de la memoria es uno de los desafíos más vitales a los que enfrentarse. El estudio y la reflexión crítica sobre las políticas culturales desarrolladas, en lo que tienen de erróneas o insatisfactorias, es otro reto, que debe llevarse a cabo incluso en los sombríos tiempos actuales. 
Por último, es vital profundizar y avanzar en experimentos radicalmente democráticos e innovadores en políticas culturales siempre que sea posible, dado que Brasil es un país de organización constitucional federativa, con gobiernos provinciales y municipales, con cierta autonomía, liderados incluso por sectores democráticos y de izquierda. El caso del Consorcio del Noreste, constituido por los gobernadores de los nueve estados de la región, todos ellos opuestos a Messias Bolsonaro, es emblemático al respecto. El Consorcio debe ser activado en favor del área de la cultura.

El amplio proceso de lucha por la democratización sustantiva de Brasil debe reunir a muchos agentes y comunidades de lugares y funciones de acción diferentes y complementarios. Los agentes culturales y las comunidades deben ser la base esencial de esta movilización, colocando la cultura, así como la educación, la ciencia y la comunicación, en el centro de la lucha democrática. El campo cultural debe asociar sus demandas de políticas culturales con las exigencias democráticas de la ciudadanía y los derechos de la sociedad, fortaleciendo su proceso de politización y entendiendo que la vida cultural depende de la conquista de la democracia y de una sociedad más justa, libre y creativa de Brasil.

Es necesario sensibilizar a las entidades de la sociedad civil, a los movimientos sociales y a la sociedad política, a sus dirigentes y partidos, sobre todo democráticos y de izquierda, para que se den cuenta de la importancia de la cultura y luchen juntos por ella y sus áreas relacionadas. Académicos e instituciones universitarias, científicas y culturales también tienen un papel relevante en este proceso de lucha, ya sea manteniendo la memoria crítica de las experiencias político-culturales expresivas que han tenido lugar en Brasil y en el mundo, o por la capacidad de analizar el presente e imaginar nuevas modalidades de acción político-cultural, en diálogo constante con la sociedad, agentes y comunidades culturales. Los gobiernos democráticos, progresistas y de izquierda deben situar las políticas culturales entre sus prioridades políticas, garantizando un clima de libertad de creación y expresión, la promoción y preservación de la diversidad cultural y el respeto a la diferencia, y permitiendo, incluso financieramente, el desarrollo de experimentos creativos e innovadores que se opongan a las culturas autoritarias y fundamentalistas. La actitud y la acción colaborativa de la totalidad de estos agentes políticos y culturales, junto con todas las fuerzas democráticas y de izquierda de la sociedad brasileña, son hoy vitales para resistir el autoritarismo, reconquistar la democracia y construir un Brasil inclusivo, soberano, diverso, plural y creativo.
Las palabras anteriores fueron escritas antes del hermoso proceso de construcción y conquista de la ley Aldir Blanc de emergencia para los sectores culturales afectados durante la pandemia. La notable capacidad de aglutinación, movilización y formulación demostrada en la invención de la ley por parte de agentes y comunidades culturales junto a sectores políticos instalados en el parlamento, en concreto diputados y senadores de partidos democráticos y progresistas, abre buenas posibilidades de futuro en tiempos tan oscuros. El movimiento posibilitó admirables victorias en las votaciones en la Cámara de Diputados y en el Senado federal e imposibilitó el poder de veto de la presidencia. El movimiento animó, organizó y politizó el campo cultural. Puso la cultura en la agenda política del país. Llevaba una significativa cantidad de recursos para el ámbito cultural. Contra todas las actitudes de gestión, la ley Aldir Blanc, en apenas unas semanas, incentivó la adhesión al Sistema Nacional de Cultura (sNc) de 570 ciudades brasileñas. El cumplimiento de la ley se convierte en un desafío enorme para la continuación de la lucha y para la consolidación de la conquista y la victoria.

\section{Fuentes}

Barbalho, Alexandre

2017 "Em tempos de crise. O MinC e a politização do campo cultural brasileiro", en Políticas Culturais em Revista, vol. 10, núm. 1, pp. 23-46.

Barbalho, Alexandre

2018 "Política cultural em tempo de crise: o Ministério da Cultura no Governo Temer", en Revista de Políticas Públicas, vol. 22, núm. 1, pp. 239-260.

BenJamin, WALTER

1967 "Tesis de filosofía de la historia", en Ensayos escogidos, Sur, Buenos Aires, pp. 43-52 [1940].

Calabre, Lia

2015 "Notas sobre os rumos das políticas culturais no Brasil nos anos de 2011-2014”, en Antonio Albino Canelas Rubim, Alexandre Barbalho y Lia Calabre (eds.), Políticas culturais no governo Dilma, Universidade Federal da Bahia, Salvador, pp. 33-48.

Costa, InÁ CAMARgo

2020 Dialética do marxismo cultural, Expressão Popular, São Paulo.

García Canclini, Néstor

1987 "Políticas culturales y crisis de desarrollo: un balance latinoamericano", en Néstor García Canclini (ed.), Políticas culturales en América Latina, Grijalbo, Buenos Aires, pp. 13-59.

García Canclini, Néstor

2001 "Definiciones en transición", en Daniel Mato (comp.) Estudios latinoamericanos sobre cultura y transformaciones sociales en tiempos de globalización, Consejo Latinoamericano de Ciencias Sociales, Buenos Aires, pp. 57-67. 
Oliveira, Cláudio

2020 "Regina Duarte e o marxismo cultural", en Cult, 4 de febrero <htts//revistacult.uol. com.br/home/regina-duarte-marxismocultural $>$.

Ramos, Murillo CÉsar

2017 "Gobiernos del PT, políticas de comunicación y pacto conservador", en Francisco Sierra Caballero y Rosa Elena Vallejo Castro (eds.), Derecho a la comunicación. Procesos regulatorios y democracia en América Latina, CIESPAL, Quito.

Rocha, JoÃo Cezar de CAstro

2020a "O verbo dominante nos vídeos dos intelectuais bolsonaristas é eliminar. E o substantivo é limpeza", en Jornal Opção, 8 de marzo <https: / /www.jornalopcao.com.br/ entrevistas /o-verbo-dominante-nos-videosdos-intelectuais-bolsonaristas-e-eliminar-e-o-substantivo-e-limpeza-239580/>.

Rocha, JoÃo Cezar de Castro

$2020 b$ "Introdução a 'Guerra cultural bolsonarista-A retórica do ódio"”, en Estado da Arte. Revista de Cultura, Artes e Ideias, 10 de abril <https: // estado da arte.estadao.com.br/guerracultural-bolsonarista-retorica-do-odio/>.
Rubim, Antonio Albino Canelas

2015 "Políticas culturais no primeiro governo Dilma: patamar rebaixado", en Antonio Albino Canelas Rubim, Alexandre Barbalho y Lia Calabre (eds.), Políticas culturais no governo Dilma, Universidade Federal da Bahia, Salvador, pp. 11-31.

Rubim, Antonio Albino Canelas

2019a "Uma visita aos conceitos de políticas culturais na América Latina", en Políticas Culturais em Revista, vol. 12, núm. 1, pp. 259-283.

Rubim, Antonio Albino Canelas

$2019 b$ "Por um conceito atualizado de política cultural" (inédito).

Stefanoni, PaBlo

2019 "El teórico de la conspiración detrás de Bolsonaro. Olavo de Carvalho y la extrema derecha en Brasil", en Nueva Sociedad, enero <https: / / nuso.org/articulo/conspiracionbolsonaro-olavo-carvalho/>.

VARella, Guilherme y JoÃo Brant

2020 "Do Estado da Cultura ao Estado anticultural", en Jorge Abrahão de Castro y Marcio Pochmann (eds.), Brasil: Estado social contra barbárie, Fundação Perseu Abramo, São Paulo, pp. 523- 538. 